\title{
Douze Études para piano de Claude Debussy: territórios de performance e experimentação composicional
}

\author{
Douze Études for piano by Claude Debussy: territories of performance and \\ compositional experimentation
}

\author{
Ricardo Henrique Serrão \\ Denise Hortência Lopes Garcia \\ Universidade Estadual de Campinas
}

\begin{abstract}
Resumo: As peças musicais intituladas "Estudos" demonstram ainda formar um campo vasto de investigação nas áreas da música. Uma delas situa-se no fato de que no século XX, o gênero Estudo potencializa-se por sua diversidade de propostas e, principalmente, por seu suporte como ambiente de experimentação composicional. Como exemplo, os Douze Études (1915) de Claude Debussy favorecem uma discussão que convergem um enfoque entre performance e composição musicais, principalmente no âmbito da análise de suas construções sonoras e uma consequente atenção à escuta concentrada do performer. Nesse sentido, esse artigo busca evidenciar os aspectos de sonoridade de alguns Estudos de Debussy, no intuito de ampliar as perspectivas que pragmatizam o gênero Estudo de forma a encará-lo como um ambiente essencialmente mecanicista dentro do campo da performance musical. Para isso, buscamos dialogar com os trabalhos de Solomos (2007) e Guigue (2011), que sugerem ser a sonoridade um paradigma composicional na música do século $\mathrm{XX}$, por exercer funções de articulação da forma musical e "integrar ao processo de gestação da obra".
\end{abstract}

Palavras-chave: Claude Debussy; harmonia; sonoridade; Estudos para piano; Música do século XX.

Abstract: The musical pieces titled "Studies" also demonstrate to form a vast field of investigation in the areas of music. One of them is the fact that in the twentieth century, the genre study is strengthened by its diversity of proposals and, mainly, by its support as an environment of compositional experimentation. As an example, Claude Debussy's Douze Études (1915) favors a discussion that converges a focus between performance and musical composition, mainly in the scope of the analysis of its sonic constructions and a consequent attention to the concentrated listening of the performer. In this sense, this article seeks to highlight the sonority aspects of some Debussy Studies, in order to broaden the perspective that pragmatizes the study genre in order to view it as an essentially mechanistic environment within the field of musical performance. To that end, we seek to dialogue with the works of Solomos (2007) and Guigue (2011), who suggest that sonority is a compositional 
MUSICA THEORICA Revista da Associação Brasileira de Teoria e Análise Musical 2018, v. 3, n. 2, p. 86-103 - Journal of the Brazilian Society for Music Theory and Analysis@ TeMA 2018 - ISSN 2525-5541

paradigm in twentieth-century music, for performing functions of articulation of the musical form and "integrating to the process of gestation of the work".

Keywords: Claude Debussy; harmony; sonority; Études for piano; 20th-century music

\subsection{O gênero musical Estudo na música do século XX}

O gênero musical Estudo desenvolve-se no século XX como também um gênero de investigação composicional. $O$ compositor pode priorizar aspectos composicionais para além das questões mecânicas instrumentais, experimentando determinados materiais ou técnicas composicionais numa espécie de laboratório de criação. Os Études en forme de canon pour piano à pedalier, op. 56, de Robert Schumann, podem ilustrar esta crescente perspectiva dos Estudos no século XX. Schumann escreveu estes Estudos explorando as potencialidades de um piano diferenciado, o piano pedal - piano com pedais similares aos do Órgão - e, também, da polifonia do canon. Isso denota um emergente interesse no romantismo pela utilização do gênero Estudo enquanto um ambiente de investigação composicional. Na perspectiva da escola do mecanismo, dificilmente encontraríamos o arranjo de um Estudo para piano em outro instrumento, pois toda composição estava submetida à lógica gestual, morfológica e mecânica do instrumento ao qual foi concebida. Essa perspectiva se amplifica quando Claude Debussy realiza o arranjo desses Estudos de Schumann para dois pianos, de forma a usufruir de seu conteúdo composicional e estético. Essa nova perspectiva se confirma, ainda mais, nos Douze Études (1915) de Debussy, obra composta pouco antes de sua morte e dedicada a Chopin, compositor que trouxe diversas críticas à escola do mecanismo propondo através de seus Estudos uma renovação na pedagogia da performance, em que a escuta concentrada e o respeito às singularidades físicas do performer sobrepuseram diversos paradigmas pedagógicos no ensino do piano.

\subsection{Claude Debussy e os Estudos de Chopin}

As propostas encontradas nos Estudos para piano de Chopin se prolongam nos Estudos de Claude Debussy. Um ponto de partida nessa investigação pode ser observado em um trecho de carta em que Debussy escreve ao editor de seus Estudos, Jacques Durand: 
Estou certo que você irá concordar comigo que não há necessidade de evidenciar o mecanismo instrumental apenas para parecer mais comprometido, um toque de charme não vai machucar ninguém. Chopin provou isso e fez com que essa necessidade se tornasse arrogante (Debussy in Durand 1927 apud Hwang 2007, p. 7).

Como exemplo, no prefácio de seus Douze Études, Debussy amplia a reflexão de Chopin sobre a heterogeneidade mecânica das mãos, propondo um olhar histórico aos cravistas barrocos.

Impor uma digitação não pode logicamente adaptar-se às diferentes conformações da mão... Nos velhos Mestres - quero dizer "nossos" admiráveis cravistas - nunca indicaram digitações, confiando, sem dúvida, na engenhosidade dos seus contemporâneos... "Nunca somos tão bem servidos que por nós mesmos". Busquemos nossas digitações! (Debussy 1915, in Prefácio dos Douze Études)

No âmbito da escrita composicional, podemos considerar que a sonoridade romântica de Chopin, em partes, conquistada pelo esforço de uma verticalização das extensões triádicas, tornou-se um recurso presente, porém resinificado na música de Debussy. Os compassos finais do Prelúdio 10, Livro 2, de Debussy, trazem um exemplo sutil dessa perspectiva. Observando a armadura de clave e as notas da melodia, poderíamos prever um acorde de função dominante $-\mathrm{C}^{9}$ em uma espécie de conclusão por suspensão.

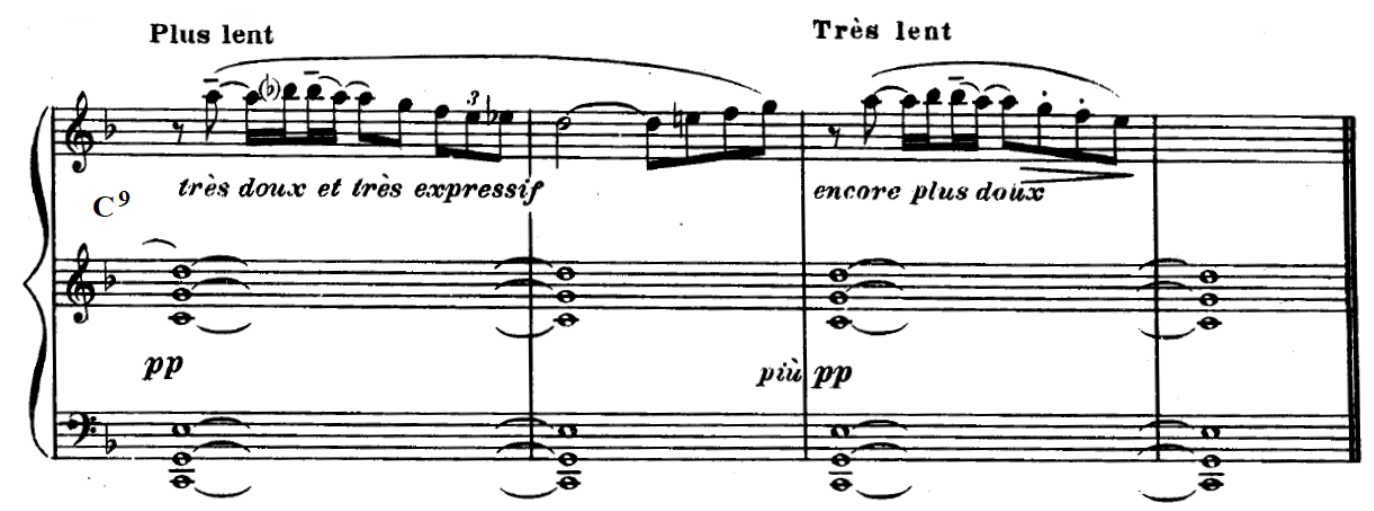

Exemplo 1: Debussy - Prélude 10, livre 2 - Resolução por decaimento de energia (c. 3033)

Pela perspectiva da articulação de sonoridades nos Estudos de Debussy, é possível também uma escuta em que a intensidade $p p$ e a não resolução tonal o "desfuncionaliza" e, portanto, contradiz as expectativas tonais sugerindo, talvez, 
MUSICA THEORICA Revista da Associação Brasileira de Teoria e Análise Musical 2018, v. 3, n. 2, p. 86-103 - Journal of the Brazilian Society for Music Theory and Analysis@ TeMA 2018 - ISSN 2525-5541

uma resolução pelo decaimento energético das dimensões timbrísticas contidas nas ressonâncias.

\subsection{Harmonia e sonoridade na obra de Claude Debussy}

Persichetti (2012) comenta sobre a harmonia no século XX considerando sua característica de convergir diversas concepções harmônicas - perspectiva que pode contribuir como ponto de partida à compreensão da escrita composicional de Debussy.

A escrita harmônica contemporânea é geralmente um processo misto que pode envolver procedimentos variados da norma da dissonância, escolha de um único idioma harmônico ou unificação de vários deles, fusão de tonalidades, simplicidade da organização sonora ou justaposição de aspectos tonais e atonais. O amálgama de concepções divergentes de formações tonais é parte de nossa linguagem harmônica. A aceitação de um procedimento não significa, necessariamente, a exclusão de outros (Persichetti 2012, p. 233).

Um pequeno trecho inicial do Prelúdio 10 de Debussy pode nos elucidar essa escrita harmônica híbrida em direção ao timbre. Em linhas gerais, observamos nos compassos iniciais da obra a coexistência de progressões tríadicas modais (c. 1-4) e de um grande gesto cadencial modulatório para Sol menor (c. 5-8). Por fim, um terceiro aspecto que nos chama a atenção está na sobreposição do intervalo de sétima maior sobre o acorde dominante - $\mathrm{D}^{7}$. Consideramos que nesse momento, apesar do gesto cadencial tonal, Debussy desenvolve a complexidade sonora moldando a ressonância do acorde $\mathrm{D}^{7}$ a partir de uma camada de inharmonicidade, gerando um contraste sonoro com relação a seus compassos anteriores.

A quase inviabilidade em utilizar-se de certas ferramentas analíticas tradicionais à compreensão desse amálgama sonoro de Debussy chama a atenção de diversos autores para uma perspectiva mais direcionada ao comportamento da complexidade sonora debussyana na articulação formal de suas obras.

Esse conjunto de relações estruturais concorre para a definição de uma elaboração compositiva dedicada à expressão de uma estética muito precisa: uma estética que busca construir formas a partir da manipulação coordenada de componentes que agem diretamente sobre a sonoridade. [...] Debussy elaborou uma rede de dimensões secundárias, sobre a qual a articulação da forma vai se apoiar, e, mais importante ainda, ele instituiu, entre essas dimensões, relações de natureza variada, de modo a reiventar, nesse nível, uma dinâmica, a qual ele, ao mesmo tempo, eliminou nos elementos que 
preservou da linguagem tonal. [...] o trabalho integrado entre a organização das intensidades, dos âmbitos [registro] e das densidades, reveste-se de um caráter particularmente significativo para expressar a forma e, portanto, para definir o estilo do compositor (Guigue 2011, p. 144-145).

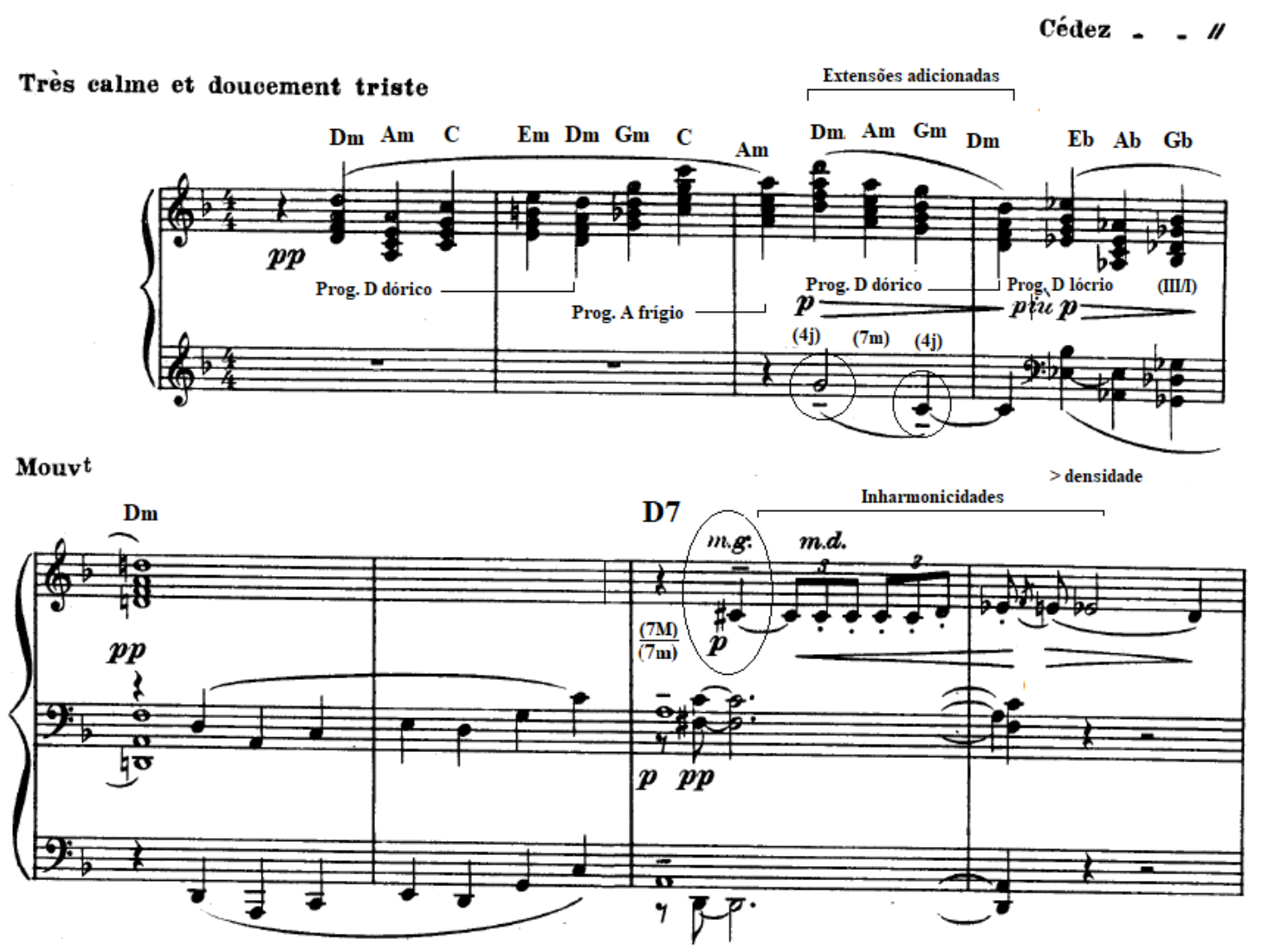

Exemplo 2: Debussy - Prélude 10, livre 2 (c. 1-8)

Nessa busca, é possível avançar sob a abordagem pragmática em que nos limitamos em descrever as diversas escalas utilizadas pelo compositor para uma reflexão mais abrangente de como estes materiais podem tornar-se componentes de uma unidade sonora complexa e dinâmica.

\section{A experimentação sonora nos Douze Études (1915) de Debussy}

Buscamos investigar os Douze Études (1915), uma das últimas obras de Debussy, sob a hipótese de que estes poderiam nos trazer evidências não somente sobre sua concepção pedagógica e mecânica instrumental do piano, mas, principalmente, sobre sua concepção composicional com a sonoridade.

Sonoridade foi o principal aspecto abordado nos Estudos de Debussy. David Kopp comenta que Debussy chamava a atenção para a necessidade de se 
transcender as estruturas formais e os limites das convenções harmônicas e assim, de certa maneira, propôs uma música baseada na cor e beleza do som (Hwang 2007, p. 7).

Alguns autores consideram a presença de uma rivalidade entre França e Alemanha na obra de Debussy pelo contexto das Guerras Napoleônicas e da Guerra Franco-Prussiana (1870-1871) em que a França foi bombardeada pela Alemanha. Segundo Ross (2007, p. 112), a guerra serviu de alerta para que outras nações da Europa percebessem que o novo império alemão possuia planos de supremacia e isso, em partes, poderia explicar a saída de Debussy e Satie ao sinfonismo de Beethoven e Wagner. "É preciso encher o ar de nova beleza", disse Stravinsky a Debussy quando silenciaram os canhões. Seyfried (2017, p. 33-34) comenta que nas correspondências de Debussy com Robert Godet - e com outras pessoas - o compositor demonstra intenções nacionalistas em seus Estudos através de uma valorização das tradições francesas de Couperin e Rameau e, também, do romantismo de Chopin. Essa rivalidade pode ser percebida por uma certa ironia na composição do Estudo I. Nesse Estudo - Pour les "cinq doigts" dedicado ao pianista austríaco Carl Czerny -, Debussy cita a coleção de 24 exercícios, Les Cinq Doigts, Op. 777, de Czerny. Nesses exercícios, o pianista deve exercitar os cinco dedos da mão direita de maneira exaustiva sobre a progressão harmônica V-I.

2 .

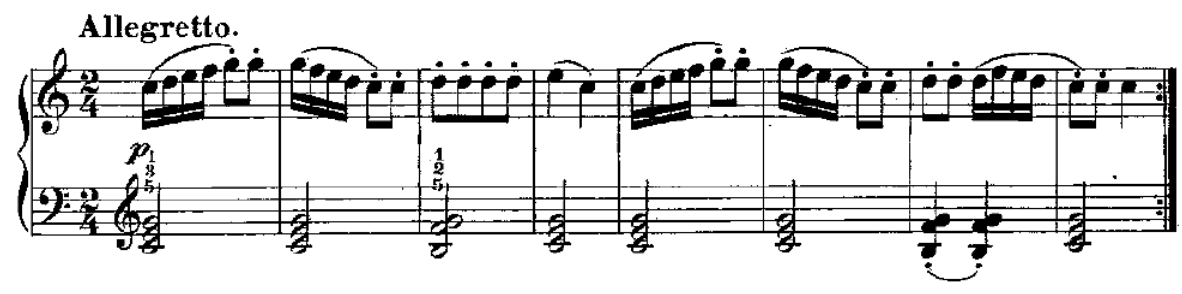

Exemplo 3: Czerny - 24 exercises, n. 2, op. 777 - exercício de mecanismo instrumental (c. 1-8)

Debussy utiliza como base esta mesma progressão harmônica, porém direciona uma considerável atenção ao desenvolvimento da sonoridade, tornando esta um objeto de estudo para além da digitação de uma escala maior por grau conjuntos. O que nos chama atenção, inicialmente, é um certo sarcasmo do compositor com a escola do mecanismo e, mais especificamente, a Czerny. Nos compassos iniciais do Estudo 1, Debussy pede o caráter expressivo "comportado" - sagement -, porém uma barra dupla divide essa breve passagem 
e prossegue com quatro compassos de grande contraste. O caráter é alterado para "animado, movimento de Gigue" - Animé (mouvt de Gigue). Além disso, a citação sobre Czerny é rapidamente modificada, a ponto de ter seu perfil melódico inicial completamente alterado no compasso 7.
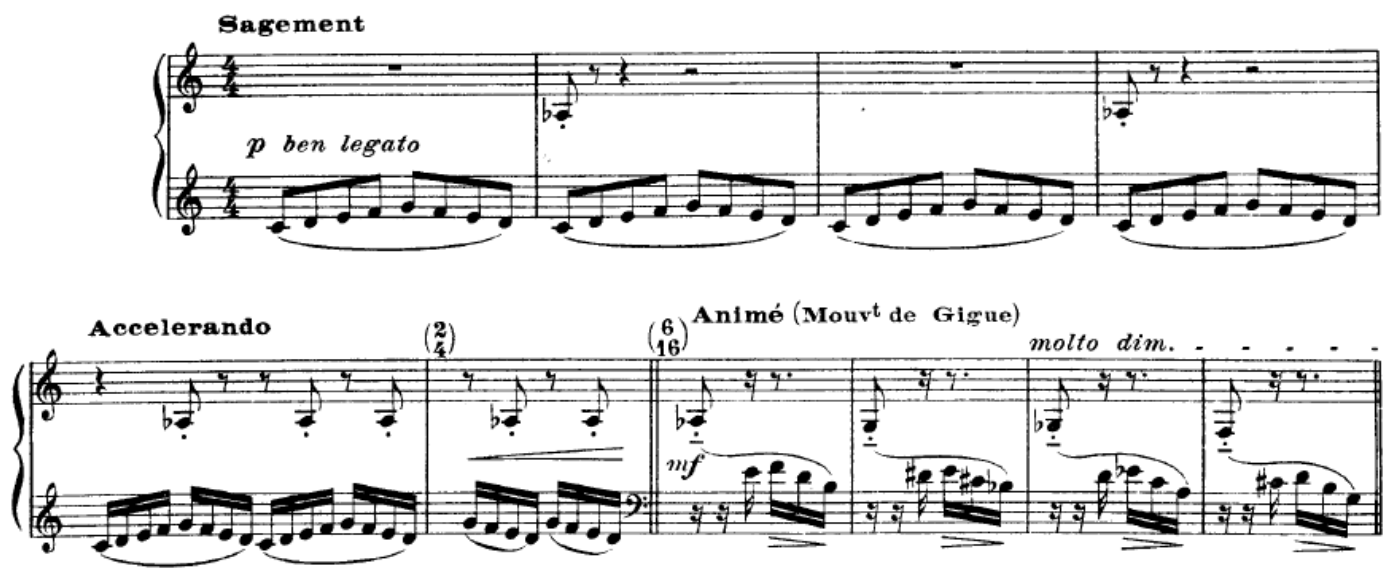

Exemplo 4: Claude Debussy - Étude 1 - Pour les cinq doigts (c. 1-15)

Sobre a sátira de Debussy, a pianista Mitsu Ushida (1991) comenta:

Debussy inicia o Estudo 1 satirizando Czerny, pobre Czerny... [toca exemplos de Czerny] Como é banal isso, como é cansativo e feio, mas enfim, é assim que Debussy começa... Então o professor diz para o aluno bem comportado: "comportado, toque isso comportadamente". [...] Então a criança começa a tocar, ela odeia isso [seu sentimento se expressa na sobreposição pela nota $\mathrm{Ab}$ na mão direita] e conforme o andamento aumenta ela odeia ainda mais e mais. Estas cinco notas são chatas demais, então a criança diz, não vou fazer isso nunca mais. Logo inicia-se uma sessão contrastante de grande fantasia, o início de um mundo de sonhos (Uchida 1991).

Portanto, considerando também as divergências de Debussy com a própria concepção pedagógica tradicional do Conservatório de Paris, é possível denotar a crítica de Debussy na mudança de caráter do trecho em que o performer sagement estaria na verdade adormecido pelo pragmatismo mecanicista. Se o Estudo das escalas em Czerny prioriza o mecanismo instrumental, Debussy, em seu Estudo 1, parece explorar as escalas enquanto sua potencialidade sonora e composicional. O campo harmônico enriquecido do romantismo permitiu o empréstimo modal das tonalidades homônimas, assim como a variação cromática das qualidades maior/menor das funções deste campos (Motte 1998). Esse enriquecimento foi fundamental para a consolidação de novas sonoridades no romantismo, que se tornaram parte fundamental de muitas obras de Debussy. Se Chopin explorou a sobreposição de diferentes 
MUSICA THEORICA Revista da Associação Brasileira de Teoria e Análise Musical 2018, v. 3, n. 2, p. 86-103 - Journal of the Brazilian Society for Music Theory and Analysis@ TeMA 2018 - ISSN 2525-5541

texturas e expandiu as relações harmônicas tonais a partir de uma harmonia por terças, Debussy parece prosseguir com estas perspectivas de maneira singular. Nos compassos 12 e 14 observamos sobreposição brusquement de uma unidade sonora distinta: um gesto melódico sobre o material escalar de Fá\# Maior, conferindo, assim, uma relação por semitom com relação à escala de Sol Maior na camada sobreposta. Nesse sentido, observamos a sobreposição de unidades sonoras distintas em diversos componentes de sua estrutura.

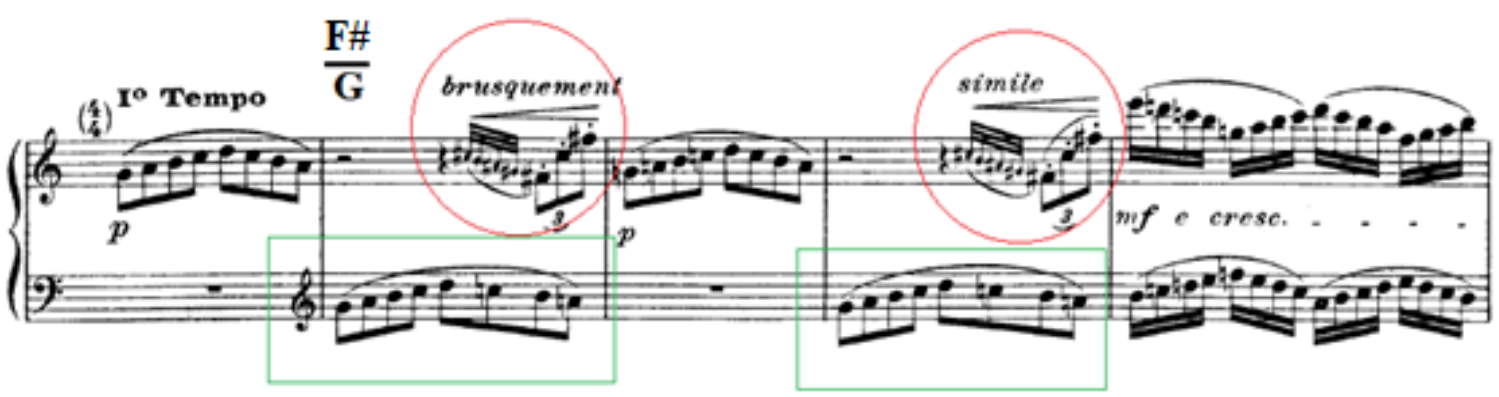

Exemplo 5: Claude Debussy - Étude 1 - Pour les cinq doigts (c. 11-15)

No Estudo Pour les quartes - assim como nos Estudos Pour les tierces, Pour les sixtes e Pour les octaves - o intervalo descrito é explorado enquanto material composicional singular. Sua potencialidade sonora favorece uma reflexão de criação e escuta para além de uma abordagem essencialmente voltada aos desafios de digitação envolvendo este intervalo. Em carta ao editor Jacques Durand, Debussy comenta: “Mesmo você ja tendo se acostumado com diversos tipos de sonoridades, irá encontrar sonoridades que nunca ouviu antes". Alguns autores sugerem que o uso das escalas pentatônicas ${ }^{1} \mathrm{e}$ tons inteiros na obra de Debussy podem denotar uma tentativa do compositor em recriar sonoridades percebidas do gamelão javanês, aspecto que também pode denotar o mimetismo de timbres - neste caso podendo ser os gongos - que ganharia forte impulso na música do século XX. Seyfried (2017, p. 90) comenta que provavelmente tenha sido na Exposition Universelle de 1889 em Paris que Debussy ouviu pela primeira vez o gameleão, que, desde então, tornou-se uma das referências musicais do compositor. Motte (1998, p. 251) e Howat (2009, p. 111) comentam que escalas comuns no gamelão, como por exemplo a escala Slendro, foram temperadas e adaptadas diatonicamente pela música ocidental, experiência que

\footnotetext{
1 Diversos instrumentos da Etiópia e Indonésia possuem afinações baseadas em escalas pentatônicas.
} 
provavelmente impactou as composições de Debussy, incluindo seu Estudo Pour les quartes.

É importante destacar que a impressão da sonoridade advinda do slendro/pentatônico é a de uma carência de fundamental, tendo em vista que cada parte instrumental da orquestra javanesa repousa sobre uma nota diferente da escala pentatônica. [...] A música do Gamelão não conhece a classificação dos acordes como consonantes e dissonantes. Dessa maneira encontramos algo muito comum na composição de Debussy sugerido pela música javanesa: a) cada nota da escala pode soar conjuntamente com qualquer outra da mesma; não existe resolução dissonante; b) não existe fundamental alguma neste flutuante mundo sonoro; c) diferentes processos simultâneos têm a mesma importância, não existindo hierarquias entre melodia e acompanhamento (Motte 1998, p. 252).

O Estudo Pour les quartes denota a influência da linguagem musical do Gamelão na escrita composicional de Debussy. Dois principais aspectos podem ser o uso das escalas pentatônicas e a construção timbrística de uma sonoridade martelé, ${ }^{2}$ em alusão à sonoridade dos metalofones do Gamelão. Além disso, as barras duplas contidas no Estudo denotam a relação entre unidades sonoras distintas, especialmente com relação aos contrastes de intensidade.

Segundo Guigue (2007, p. 126), na obra de Debussy não encontramos com grande frequência o uso de dinâmicas com intensidades elevadas $(f, f f, f f f)$. Parte importante de sua obra evoluiu em torno do pianíssimo $(p p, p)$. Grande parte das obras para piano não saem dessa amplitude (Prelúdes, Images, Six épigraphes Antiques). Nesse sentido, o autor destaca que os Douze Ètudes (1915) reconhecidos como um dos mais significativos legados musicais de Debussy abrem espaço para um amplo espectro de intensidades.

Sob esse ângulo, o ordenamento de contrastes abruptos de volumes sonoros entre dois instantes imediatamente consecutivos adquire notável relevo. Devido ao fato de que esses contrastes provocam uma ruptura na continuidade sonora vigente, geralmente em baixos níveis de amplitude, eles se tornam marcadores per se na superfície perceptível, o que pode constituir um indício do compositor em produzir uma manifestação sonora na superfície que reflita uma articulação estrutural (Guigue 2011, p. 126).

\footnotetext{
${ }^{2}$ Marguerite Long (1972 apud Seyfried, 2017) destaca que um comentário muito frequente de Debussy era: "Não podemos esquecer que o piano possui martelos".
} 
MUSICA THEORICA Revista da Associação Brasileira de Teoria e Análise Musical 2018, v. 3, n. 2, p. 86-103 - Journal of the Brazilian Society for Music Theory and Analysis @ TeMA 2018 - ISSN 2525-5541

Um exemplo dessa demarcação pode estar na sonoridade martelé compasso 7 - da qual o compositor apresenta componentes sonoros contrastantes aos compassos que o precedem, em especial, as intensidades e articulações métricas.

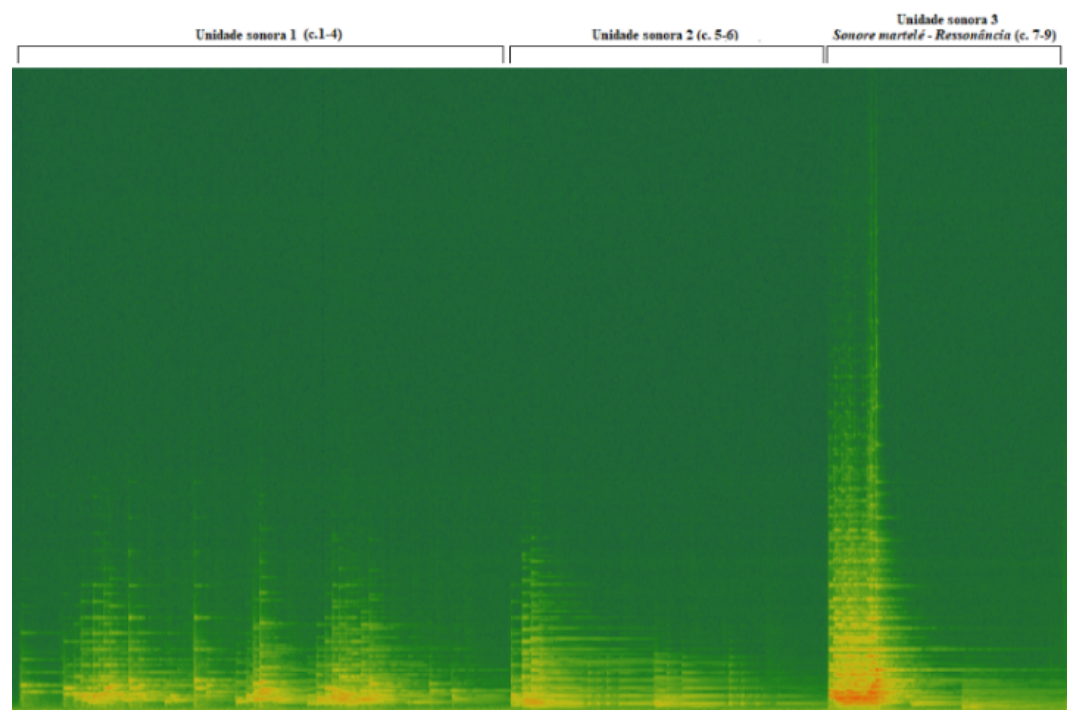

Figura 1: Claude Debussy - Étude 3 - Pour les quartes - unidades sonoras opostas (c. 410; pno.: Uchida)

Debussy parece propor uma escuta concentrada para as ressonâncias pentatônicas quartais: uma primeira utilizando-se exclusivamente do modo Dó pentatônico menor e, em seguida, a repetição do gesto com o acréscimo do trítono - Lá, e Ré (notas evitadas da pentatônica).

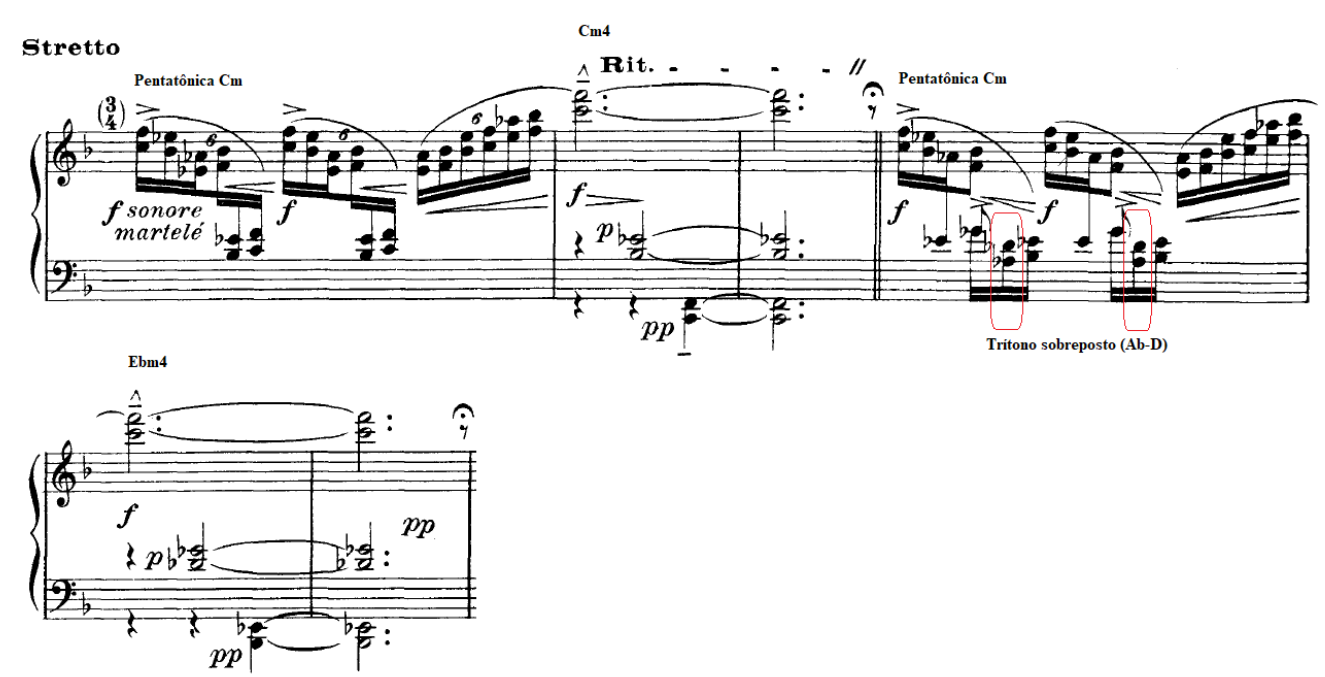

Exemplo 6: Claude Debussy - Pour les quartes. (c. 4-9) 
Segundo Bullock (2008, p. 33), para uma análise do timbre, podemos considerar que qualquer som possui suas características de frequência e intensidade no tempo, porém também podemos observar características coexistentes na formação do timbre como por exemplo o nível de noisiness no espectro sonoro, ou seja, uma espécie de "mancha" próxima às frequências mais nítidas, ou, em outras palavras, frequências transientes bem próximas às de maior definição que interagem na construção sonora. Nesse sentido, o trecho destacado do Estudo pour les quartes apresenta uma articulação do componente noisiness tendo seu pico máximo na reiteração da frase com o trítono adicionado.

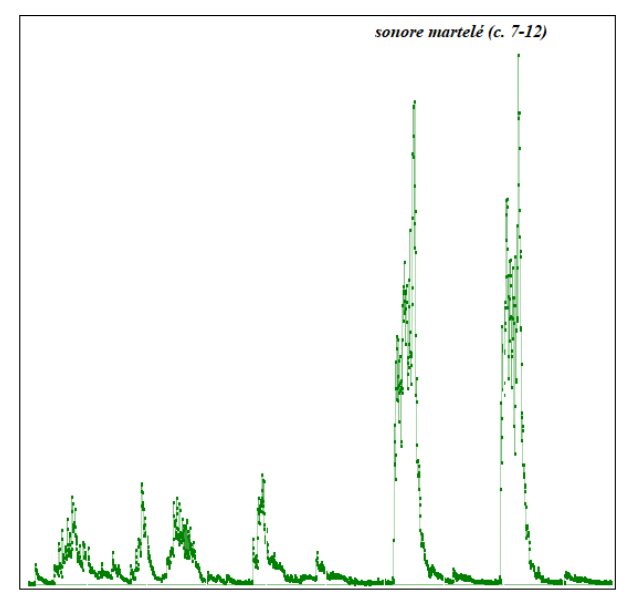

Figura 2: Claude Debussy - Pour les quartes. (c. 7-12 - pno.: Uchida)

Essa recriação timbrística destacada na sonore martelé colabora para um processo que será amplificado durante a música do século XX: a imersão à complexidade imanente do som e uma consequente expansão das investigações sobre maneiras de execução na performance e na própria morfologia dos instrumentos. O desenvolvimento sonoro indissociado das intensidades talvez seja o principal aspecto abordado no Estudo Pour les huit doigts. Isso se confere pela maneira detalhada como este componente é abordado na escrita e por uma espécie de desenvolvimento harmônico estático. Guigue aponta para uma "dependência" dos diversos componentes com relação ao desenvolvimento das intensidades.

No nível secundário, as densidades, as modalidades de distribuição dos sons no espaço e no tempo, o modo de execução são fixados de uma vez por todas, sendo raras e de pouca envergadura as escapadas. Toda energia cinética do Estudo repousa na dinâmica de três dimensões, que agem em estreita correlação: a intensidade, o âmbito e a partição. Em verdade, essas duas 
MUSICA THEORICA Revista da Associação Brasileira de Teoria e Análise Musical 2018, v. 3, n. 2, p. 86-103 - Journal of the Brazilian Society for Music Theory and Analysis@ TeMA 2018 - ISSN 2525-5541

últimas são dependentes da primeira, pois é a intensidade, de fato, que propulsa a música por meio do arquétipo da progressão, limitando-se o âmbito e a partição em acompanhar a energia do processo (Guigue, 2011, p. 135).

Nesse sentido, observamos pelo descritor loudness parte das características relacionadas às intensidades e seu comportamento na macroforma do Estudo, a partir da performance do pianista Thibaudet.

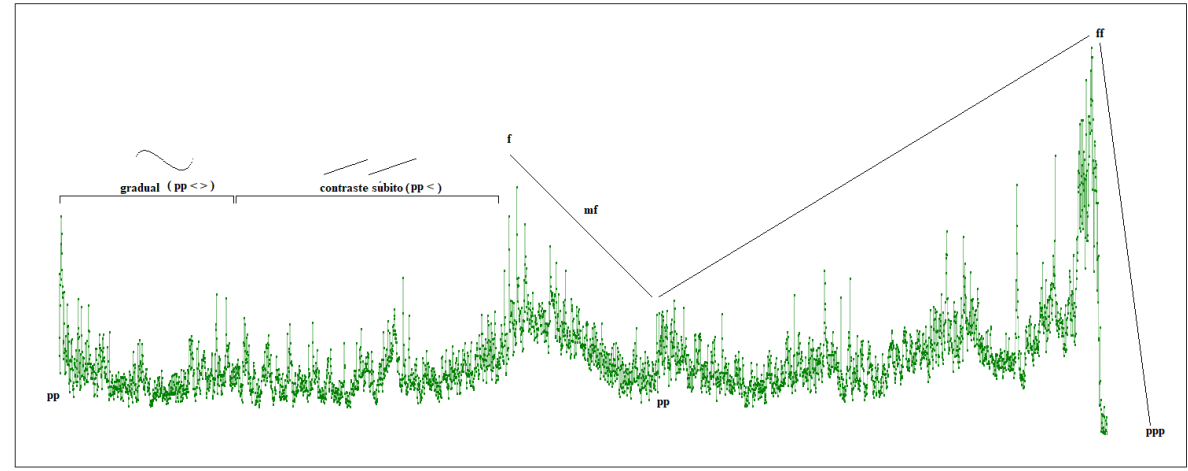

Figura 3: Debussy - Étude pour les huit doigts - Intensidade e macroforma (pno.:

Thibaudet)

Nota-se que a representação das intensidades pelo descritor loudness permite-nos observar no último intervalo do Estudo que o performer, ao invés de seguir a indicação piano, aplicou a intensidade mais baixa de toda sua performance. Em nosso ponto de vista, essa interpretação colaborou em amplificar as relações dos níveis de intensidade abordados no Estudo, contrastes que foram evidenciados pelo compositor na construção macroformal do Estudo e também em aspectos da microestrutura, como é o exemplo dos últimos compassos do Estudo.

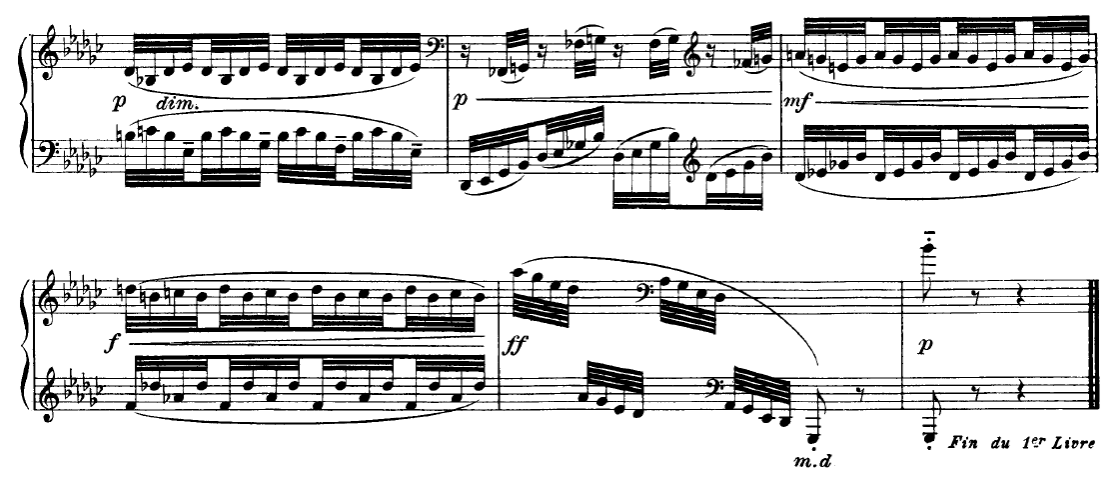

Exemplo 7: Debussy - Étude pour les huit doigts - Intensidade e microforma (c. 64-69) 
Talvez o Estudo 10 - Pour les sonorites opposées - seja um dos primeiros Estudos a trazer literalmente em seu título uma preocupação com a articulação formal pelo viés dos contrastes sonoros. Segundo Guigue (1996, p. 368 apud Narmour 1990), este Estudo subverte grande parte dos conceitos formais clássicos, em particular, as regras de coerência e continuidade sonoras, enfraquecendo as expectativas implícitas de realização do sistema tonal. Em linhas gerais, Debussy utiliza barras duplas de compasso para separar unidades sonoras contrastantes, sonoridades complexas por sua diversidade de componentes, como articulação, densidade, ataques, intensidades, tempo de ressonância, sobreposição por camadas, dentre outros. Segundo Guigue, a criação de uma determinada sonoridade a partir do trabalho com seus diversos componentes pode favorecer a geração de uma "assinatura sonora".

Uma assinatura sonora é o conjunto de componentes que formam a característica de um objeto sonoro e que o torna singular com relação aos outros objetos sonoros da peça. [...] Quando identificamos uma assinatura sonora, é possível delimitar estruturas formais a partir delas. Nesse sentido, uma seção da forma pode ser gerada por uma assinatura sonora. Uma assinatura sonora pode possuir o componente da intensidade de maneira a contrastar com as intensidades de outras sonoridades da peça. Então teremos um contraste adjacente como assinatura sonora (Guigue 2011, p. 126-128).

Na primeira oposição descrita por Debussy - barra dupla entre compassos 6-7 - observamos um detalhamento na notação que demonstra as contribuições da escrita na composição da sonoridade. Isso não indica que a sonoridade possa ser completamente descrita pela notação, mas, sim, que podemos estimular este complexo aproveitando-se da escrita - perspectiva que será amplificada na música do século $X X$.

Debussy menciona o problema do timbre em si pela primeira vez no Estudo Pour les sonorites opposées. Esse Estudo requer uma atenção privilegiada do performer aos aspectos de sonoridade e timbre, até então não tão diretamente abordados na literatura pianística. O pianista deve conquistar a habilidade de controle às súbitas gradações do toque e da intensidade assim como projetá-las de forma contrastante nos componentes de âmbito, textura, intensidade, articulação e densidade. Estes componentes estão sempre envolvidos em texturas e linhas contrapontísticas, tornando-se desafios ao performer. Junto ao aproveitamento do pedal, esse Estudo pode produzir uma complexidade sonora orquestral (Hwang 2007, p. 102). 
MUSICA THEORICA Revista da Associação Brasileira de Teoria e Análise Musical 2018, v. 3, n. 2, p. 86-103 - Journal of the Brazilian Society for Music Theory

Os diferentes pianos - dolente e expressif et profond - separados pelas barras duplas evocam uma escuta concentrada pela alteração sutil da intensidade no complexo sonoro, variação que exige também do performer um aspecto criativo com relação à exploração do timbre.
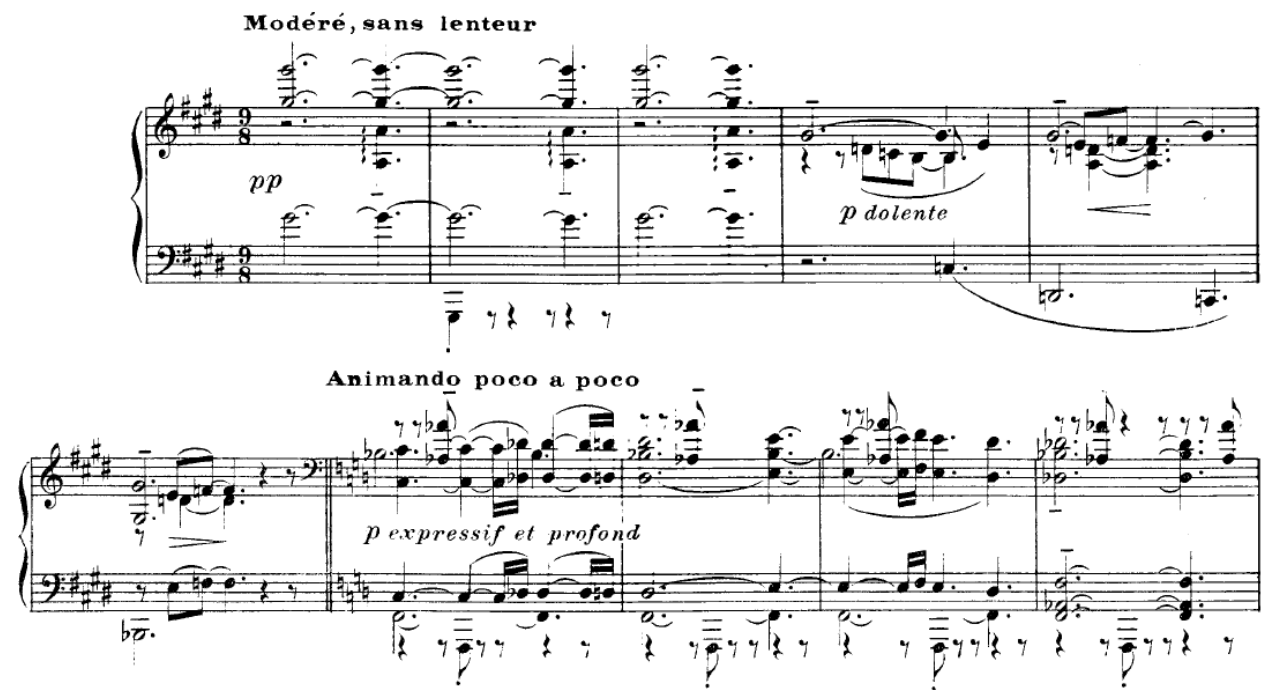

Exemplo 8: Debussy - Pour les sonorites opposées - Diferentes pianos entre sessões A e B (c. 1-10)

O contraste sonoro entre os compassos 11 e 20 nos permite observar a alteração de diversos componentes sonoros, como suas alturas, densidades, articulações, ritmos, ressonâncias e intensidades.

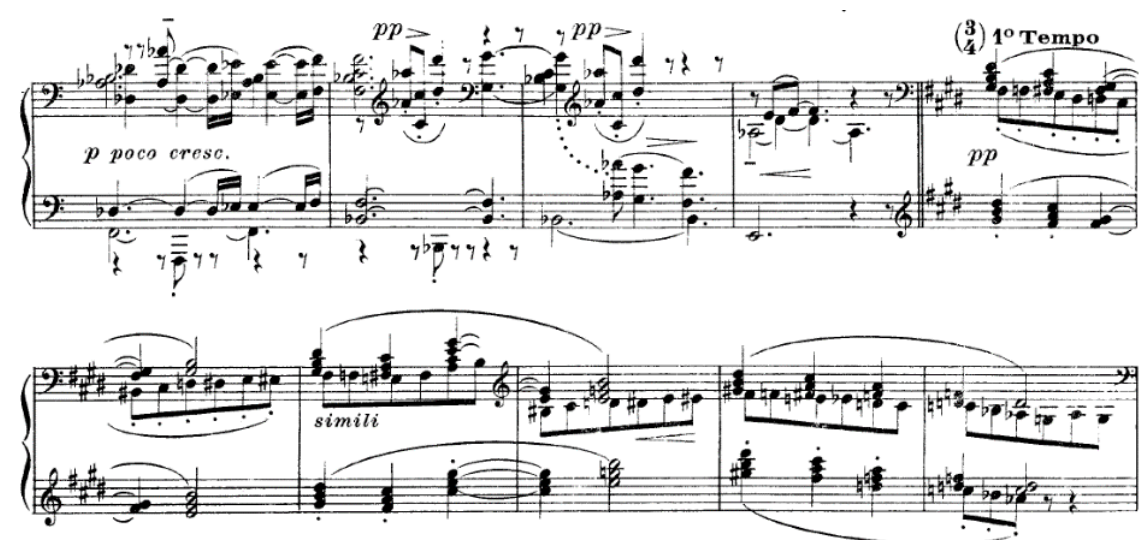

Exemplo 9: Debussy - Pour les sonorites opposées - contraste sonoro entre sessões B e C (c. 11-20)

Em uma perspectiva macroformal, observamos oposições no perfil sonoro com relação à percepção de rugosidade espectral - sharpness - ou seja, a percepção de ataques consecutivos que impedem o decaimento das intensidades. Observando características de rugosidade na sonoridade, nota-se uma quase 
alternância de contraste entre sonoridades com maior e menor nível de rugosidade. Na Figura 4, temos, portanto, a representação comparativa entre intensidade (amarelo) e rugosidade (branco), ambas representadas sob os eixos frequência/tempo. Quanto mais alinhada na horizontal, maior a rugosidade sonora, e quanto mais alta a linha amarela, maior a intensidade. Nesse sentido, é possível observar que Debussy explora as ressonâncias em suas dinâmicas mais baixas e as rugosidades por ataques mais contínuos em intensidades mais elevadas.

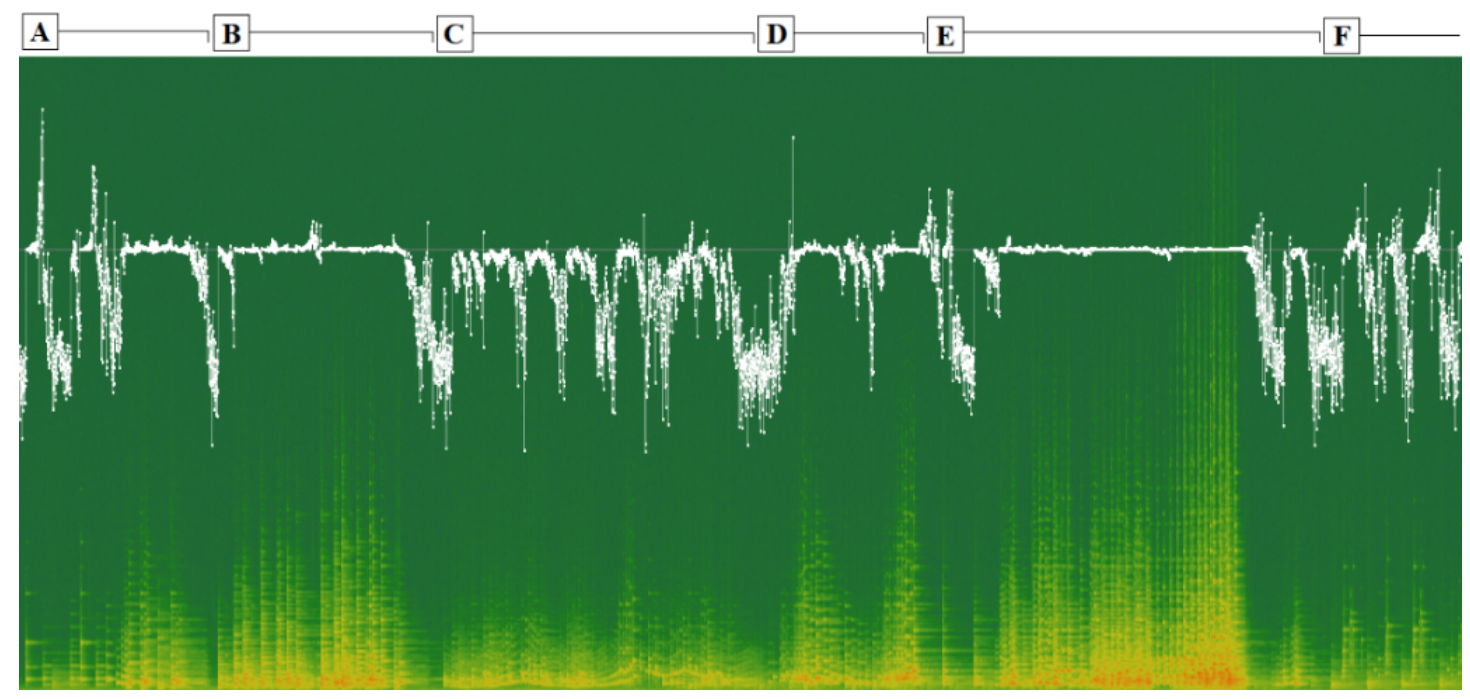

Figura 4: Debussy - Pour les sonorites opposées - Relações rugosidade-intensidade, sessões A-F

Parte dos Estudos compostos durante o século XX tornam-se importantes obras pedagógicas não somente à performance, mas, também, à análise e à composição musicais. Nesse sentido, é possível observar uma certa desvalorização dessas obras por diversas instituições de ensino, devido ao fato de ainda tratarem os Estudos como materiais exclusivamente voltados ao treinamento mecanicista na performance musical. Dessa forma, podemos considerar que os Estudos de Debussy acabam por propor uma formação musical mais abrangente, favorecendo a compreensão da linguagem musical nos âmbitos da criação, análise e interpretação musicais.

Debussy, no entanto, estabeleceu um certo número de propostas técnicas, mostrou caminhos de acesso a um sistema baseado no som, que tem valor de ferramentas, o que significa poderem ser reutilizadas em múltiplas situações e com total independência do contexto estilístico que presidiu sua elaboração na origem. (Guigue 2011, p. 144-145) 
A análise dos Estudos de Debussy, partindo da perspectiva de sua influência pela obra de Chopin, buscou evidenciar um caminho de evolução da abordagem sonora no ambiente dos Estudos. Estes Estudos evocam a escuta do performer, que, no momento da performance, aproxima-se e participa das investigações sonoras propostas pelo compositor - perspectiva que acreditamos ter sido compreendida por Debussy. Long (1960, p. 34 apud Herold) comenta que Debussy cria uma relação entre "timbre e forma" pela analogia do "sensível e inteligível" ao provocar seu professor de composição do Conservatório de Paris, Ernest Guiraud: "Ele não tem a teoria suficiente para entender...o prazer é a regra". Esta provocação parece propor uma compreensão das obras a partir da sonoridade e de suas relações com a forma. Confrontando "forma" e "timbre" temos uma analogia com a "regra" e o "prazer", até então estruturas essencialmente opostas. Porém, não encontramos aqui uma forma de representar o "prazer" da escuta, retomamos o apontamento de que essa perspectiva, de certo modo mais "objetiva" em analisar comportamentos sonoros, não responde à diversas questões que envolvem a subjetividade da escuta. Buscamos nessa abordagem por representações simbólicas - partitura e espectrograma -, investigar como a sonoridade possivelmente esteve entre uma das preocupações composicionais - e talvez pedagógicas - dos Estudos compostos entre o final do século XIX e início do século XX.

\section{Considerações finais}

As peças musicais intituladas "Estudos" demonstram ainda formar um campo vasto de investigação nas áreas da música. Uma delas situa-se no fato de que no século $X X$, o gênero Estudo potencializa-se por sua diversidade de propostas e, principalmente, por seu suporte como ambiente de experimentação composicional. Como exemplo, os Douze Études (1915) de Claude Debussy favorecem uma discussão que convergem um enfoque entre performance e composição musicais, principalmente no âmbito da análise de suas construções sonoras e uma consequente atenção à escuta concentrada do performer. Uma das problemáticas que nos chama a atenção é que ainda hoje parece permenecer um certo "senso comum" de que o gênero Estudo consiste, exclusivamente, de peças voltadas ao treinamento mecânico instrumental, perspectiva que buscamos contradizer em prol de uma formação musical mais profunda expressivamente e intelectualmente. O pragmatismo da escola do mecanismo se mantém em 
diversos programas de curso de instituições de ensino de música na atualidade, de forma a enquadrar um amplo repertório de Estudos sob uma ótica engessada e mecanicista. Consideramos que os Estudos de compositores como Chopin, Debussy e Arthur Kampela, compositores-performers com significativa produção sobre o gênero, favoreceram um olhar expandido para a profundidade do gênero, principalmente para sua contribuição à música dos séculos XX e XXI. Acredito que os programas de curso de música possam refletir sobre a trajetória histórica do gênero Estudo de forma a aproveitá-lo em seu potencial interdisciplinar e, por fim, tomarem cuidados com a inconsistência que propostas mecanicistas podem trazer na formação dos músicos.

\section{Referências}

1. Gigue, Didier. 2011. Estética da Sonoridade: A Herança de Debussy na Música para Piano do Século XX. Ed. Perspectiva. CNPQ; UFPB.

2. ___ 1996. Une Étude "Pour les sonorités opposées": Pour une analyse orientée objets de l'oeuvre pour piano de Debussy et de la musique du XX siècle. Doutorado, Paris, École des hautes études en sciences sociales.

3. 1998. Debussy versus Schnebel: sobre a emancipação da composição e da análise no Séc. XX. In: Opus 5, vol.5, n. 5. Rio de Janeiro: Anppom, Agosto, p. 19-47.

4. Herold, Nathalie. 2011. Timbre and Form: timbral dimension of form in the piano music of the first half of the nineteenth century. Doctorat, Université de Strasbourg.

5. Howat, Roy. 2009. The Art of French Piano Music: Debussy, Ravel, Fauré, Chabrier. New Haven e London: Yale University Press.

6. Long, Marguerite. 1972. At the piano with Claude Debussy. London: J. M. D. \& S. Ltd.

7. Motte, Dieter de la. 1998. Armonia. Barcelona: Editorial Labor.

8. Durand, Jacques. 1927. Debussy: Lettres a son edditeur. Paris.

9. Valias, Leon. 1973. Claude Debussy: His Life and Works. Trad. Maire e Grace O’Brien. New York: Dover.

10. Uchida, Mitsuko. 1991. Played 12 Études by Claude Debussy. Direção: G. Wubbolt, Philips Classics. 
MUSICA THEORICA Revista da Associação Brasileira de Teoria e Análise Musical 2018, v. 3, n. 2, p. 86-103 - Journal of the Brazilian Society for Music Theory and Analysis@ TeMA 2018 - ISSN 2525-5541

11. Monteiro, Adriano Claro. 2012. Criação e performance musical no contexto dos instrumentos musicais digitais. Dissertação de Mestrado, Universidade Estadual de Campinas.

12. Pereira, Erica. 2009. Estudos sobre uma ferramenta de classificação musical. Campinas, Dissertação de Mestrado, Universidade Estadual de Campinas.

13. Solomos, Makis. 2013. De la musique au son: l'emergence du son das la musique des Xxe-XXIe siècles. Presses Universitaires de Rennes.

14. Wheeldon, Marianne. 2017. Debussy's legacy and the construction of reputation. Oxford: Oxford University Press.

15. Rosseti, Danilo. 2017. A percepção do timbre em Farben op. 16 n. 3 de Schoenberg: uma abordagem estética e psicoacústica. Revista Música, USP, $\mathrm{n}$. 17, p. 292-324. 